\title{
High-Users of Acute Care in a Teaching Hospital: A Retrospective Chart Review and Survey of Primary Care Physicians
}

Arpita Gantayet, MD, MASc, Pamela Mathura, MBA, Alexis Fong-Leboeuf, BMSc, Natalie McMurtry, MBA, Julie Zhang, MSc, Finlay A. McAlister, MD, MSc, Narmin Kassam, MD, MHPE

\section{About the Authors}

Arpita Gantayet, MD, MASc, is a Resident in the Department of Internal Medicine, University of Alberta, Edmonton, Alberta, Canada Pamela Mathura, MBA, is an Improvement Specialist for the Department Medicine, Alberta Health Services and a Clinical Lecturer in the Department Medicine, University of Alberta, Edmonton, Alberta, Canada

Alexis Fong-Leboeuf, BMSc, is a Medical Student at the University of Alberta, Edmonton, Alberta, Canada.

Natalie McMurtry, MBA, is an Executive Director in Operations and Facility Development at Alberta Health Services, Edmonton, Alberta, Canada

Julie Zhang, MSc. is a Performance Improvement Manager at the University of Alberta Hospital, Edmonton, Alberta, Canada Finlay A. McAlister, MD, MSc is a Professor of General Internal Medicine and Alberta Health Services Chair in Cardiovascular Outcomes Research, University of Alberta, Edmonton, Canada

Narmin Kassam, MD, MHPE is Professor of General Internal Medicine and Deputy Clinical Department Chair in the Department of Medicine, University of Alberta, Edmonton, Canada

Corresponding Author: arpita.gantayet@gmail.com

Submitted: April 14, 2019. Accepted: October 18, 2019. Published: August 27, 2020. DOI: 10.22374/cjgim.v15i3.363

\section{ABSTRACT Purpose}

To characterize high-users (HUs) of inpatient units, obtain insights from their primary care physicians (PCPs) and identify factors that can be modified to reduce resource use.

\section{Method}

The study design included retrospective chart reviews of high-user patients and qualitative surveys of their PCPs. HUs were defined as adults with 3 or more admissions to an index tertiary teaching hospital in Edmonton as well as a cumulative length of stay (cLOS) greater than 30 days at any hospital in the province of Alberta, between September 1, 2015 and September 30, 2016. The charts of HUs were reviewed to assess demographics, admitting and consulting services, medical profile, social profile, community supports, and scores on pre-existing risk-stratification tools to identify patient factors that might be characteristic of HUs. Additionally, a survey comprising 12 multiple-choice and 8 short-answer questions was faxed to their PCPs to assess HU attitudes and behaviors and collect recommendations to prevent high use of acute care.

\section{Results}

Of 125 HUs (median 62 years old, 5 admissions, cLOS 49 days, 14 emergency department (ED) visits, 10 medications), $74 \%$ lived at home, $86 \%$ had a PCP, $56 \%$ received homecare pre-admission and $34 \%$ had at least one critical care admission. HUs accounted for 2474 admissions or ED 
visits (median 14, IQR 10-22) at all sites in the year studied; 41\% of their 1605 ED visits and $21 \%$ of their 869 admissions were at other hospitals. Their most prevalent comorbidities were hypertension, depression, and diabetes. 49 responses were received to 114 faxed surveys ( $43 \%$ response rate). Only 14 of 49 responding PCPs suggested interventions to address ED revisits and readmissions; PCPs most frequently cited living conditions and lack of social supports as key causative factors.

\section{Conclusions}

We have characterized high-user patients and discussed PCP perspectives and strategies to optimize their healthcare use.

\section{Resume \\ Objet}

Caractériser les grands utilisateurs (HU) des unités d'hospitalisation, obtenir des informations de leurs médecins de soins primaires (PCP) et identifier les facteurs qui peuvent être modifiés pour réduire l'utilisation des ressources.

\section{Méthode}

La conception de létude comprenait des examens rétrospectifs de dossiers de patients très utilisateurs et des enquêtes qualitatives sur leurs PPC. Les UH ont été définis comme des adultes ayant été admis à trois reprises ou plus dans un hôpital universitaire tertiaire d'Edmonton et dont la durée de séjour cumulée (DSC) est supérieure à 30 jours dans n’importe quel hôpital de la province de l'Alberta, entre le 1er septembre 2015 et le 30 septembre 2016. Les tableaux des HU ont été examinés afin d'évaluer les données démographiques, les services d’admission et de consultation, le profil médical, le profil social, les soutiens communautaires et les scores des outils de stratification des risques préexistants afin d'identifier les facteurs des patients qui pourraient être caractéristiques des HU. En outre, une enquête comprenant 12 questions à choix multiple et 8 questions à réponse courte a été envoyée par fax à leurs PCP afin d'évaluer les attitudes et les comportements des $\mathrm{HU}$ et de recueillir des recommandations pour prévenir un recours élevé aux soins de courte durée.

\section{Résultats}

Sur 125 HU (âge médian 62 ans, 5 admissions, cLOS 49 jours, 14 visites aux urgences, 10 médicaments), $74 \%$ vivaient à domicile, $86 \%$ avaient un PCP, $56 \%$ recevaient des soins à domicile avant leur admission et $34 \%$ avaient au moins une admission en soins intensifs. Les HU ont représenté 2474 admissions ou visites aux urgences (médiane 14, IQR 10-22) dans tous les sites au cours de l'année étudiée ; $41 \%$ de leurs 1605 visites aux urgences et $21 \%$ de leurs 869 admissions se sont faites dans d’autres hôpitaux. Leurs comorbidités les plus fréquentes étaient l'hypertension, la dépression et le diabète. 49 réponses ont été reçues pour 114 enquêtes envoyées par fax (taux de réponse de $43 \%$ ). Seuls 14 des 49 PCP ayant répondu ont suggéré des interventions pour remédier aux problèmes des visites aux urgences et des réadmissions; les PCP ont le plus souvent cité les conditions de vie et le manque de soutien social comme principaux facteurs de causalité.

\section{Conclusions}

Nous avons caractérisé les patients grands utilisateurs et discuté des perspectives et des stratégies de la PCP pour optimiser leur utilisation des soins de santé. 
As life expectancy increases and healthcare needs become more complex, it is becoming increasingly important to improve efficiency in healthcare delivery. ${ }^{1,2}$ It has been observed in various settings that a small proportion of the population accounts for disproportionate use of healthcare resources; $5 \%$ of the population accounted for $64 \%$ of total health care spending in Ontario $^{3}$ and $66 \%$ in Alberta. ${ }^{4}$ The biggest driver of these costs are inpatient (IP) admissions. ${ }^{1,3}$ Although multiple risk scores have been developed to predict single readmissions after hospital discharge ${ }^{5-7}$ there are few risk-stratification tools to predict which individuals will become high system users.

The objective of this study was to use a patient-focused approach to gain insights into high-users (HUs) and potential approaches to optimizing their care. The goal was to identify and characterize current HUs, obtain insights from their primary care physicians (PCPs) on their healthcare behaviors and attitudes, discover patient and system factors that predispose them to frequent readmissions, and to suggest strategies to intervene against modifiable factors.

\section{METHODS}

This study was performed at a large tertiary care teaching hospital, the University of Alberta Hospital (UAH), Edmonton between Sep 1, 2015 and Sep 30, 2016. The study design included chart reviews of high-user patients and qualitative surveys of their PCPs. As per the Canadian Institute for Health Information (CIHI) definition, HUs were any adult patients with three or more admissions at our index hospital and cumulative length of stay (cLOS) greater than 30 days at any hospital in the province of Alberta, during that year. Patients who met the HU definition were included even if they died in the hospital or during the study period.

High user data was obtained from the Alberta Health Services (AHS) medical site administrative office using the Data Integration Monitoring and Reporting (DIMR) unit. We used DIMR to collect all data on visits to ED or acute care hospitals anywhere in the province of Alberta - this allowed us to track resource use by HUs regardless of where else they received care in the province. The descriptive variables derived from the UAH local database and DIMR were organized into the following categories; patient gender, age at last admit, postal code, date of last admission between Sep 1/15 - Sep 30/16, number of UAH admissions in study period, number of non-UAH admissions, number of UAH ED visits, number of non-UAH ED visits, cumulative LOS (days) between Sep 1/15 - Sep 30/16 at UAH only and cumulative LOS (days) between Sep 1/15 - Sep 30/16 at all hospitals in Alberta. DIMR also provided data on whether the identified HUs had any admissions in the prior two years if the $\mathrm{HU}$ patient was deceased at the time of analysis, and the number of ambulance arrivals. We obtained the most common admitting diagnosis list from UAH under the hospital's International Statistical Classification of Disease (ICD) codes. HU data was derived for all specialties except Obstetrics/Gynecology, which is not available at the UAH site, and Pediatrics, as this patient population was not the focus of the study. Admitting service was categorized by specialties; General Internal Medicine (GIM)/Cardiology/Critical care/Gastroenterology/Hematology/ Nephrology/Family Medicine/Surgical specialties including ENT/ Psychiatry/Geriatrics. Quantitative variables were loaded on a 'Dashboard' database created by the Performance Improvement Manager at UAH and analysis was performed by the first author using its filter applications. The data was documented as number counts and ranges of minimum to maximum, where applicable. Excel worksheets were then used by the first author to calculate proportions, percentages as well as medians with an interquartile range from the $25^{\text {th }}$ to $75^{\text {th }}$ percentile.

We obtained ethics approval for chart reviews and PCP surveys, with a waiver of informed patient consent, from the University of Alberta Research Ethics Board (Pro00073914). Physician (PCP) informed consent was obtained by faxing a consent sheet along with the survey. Chart reviews were standardized by the first author using a list of definitions and categorization protocols and were performed by the first and third authors in this study. Only charts for the last admission in the study period were reviewed for each $\mathrm{HU}$, as comprehensive data collection and analysis was not feasible given the large number of admissions for all HUs combined. Descriptive variables derived from the chart review were categorized as living facility at the time of the last admission, time lived in that facility, prior or current home care, duration of home care, types of home supports, types of inter-professional care supports in the community, independent for all activities of daily living (ADLs) and iADLs (in the form of yes, no or unknown), number of regularly prescribed, scheduled medications at the last admission, list of discharge medications after the last admission in the study period, the cumulative number of specialties involved and goals of care documented in the chart at the time of the last admission in the study period. Comorbidities listed in the chart under 'Past Medical History' were categorized into Neurologic, Cardiovascular, Pulmonary Gastrointestinal, Hematologic, Nephrology, Oncology, Infectious Diseases, Rheumatology, Endocrinology, Psychiatry, Geriatrics, Transplant and Other. These comorbidities were used to calculate the Charlson Comorbidities score.

To determine if existing scores are predictive of these highusers, we calculated LACE and FAM-FACE-SG scores for each HU based on their last admission during the study period. The LACE score is a 19-point score which assigns points for length of stay, acuity of admission, comorbidities and number 
of ED visits and is considered high risk for readmission if $\geq 10 .{ }^{5}$ The FAM-FACE-SG score was modified to include age, number of admissions, frequency of ED use ( $\geq 3 \mathrm{ED}$ visits in 6 months before index admission), antidepressant use in past year, Charlson Comorbidity score, ${ }^{9}$ ESRD on dialysis and lasix dose (intravenous $40 \mathrm{mg}$ and above during last admission), but no need for financial assistance or subsidized ward stay, with a score $\geq 14$ considered high risk. ${ }^{8}$

PCP affiliation was determined by the third author by checking if the HU had a physician name listed in their medical record. If yes, the PCP's medical specialty and contact information was obtained from the College of Physicians and Surgeons of Alberta (CPSA) website; some PCPs could not be contacted as their contacts were not available on the CPSA website or they were deceased. For the remainder, we first contacted the PCP offices by phone and clarified if the patient had ever been affiliated with the PCP. If yes, we additionally asked for permission to send a survey and determined the accurate fax number or email address. The first round of surveys was sent by fax or email between February 18, 2018 - March 2, 2018. If a response was not received within two weeks, a reminder call was given and surveys were re-faxed. All responses received by May 30, 2018, were included in the analysis.

The survey consisted of 12 multiple-choice questions and 8 short answer questions. A sample survey can be seen in Table S2 in the Supporting Information section. All analysis of PCP surveys was performed by the first author. For the multiple-choice questions, when multiple options were selected, all options were included in the count. Unfortunately, not all PCPs responded to every question, therefore each question has a different number of responses. We calculated the percentage of each response in excel, using a common denominator, as a proportion of the total number of PCPs who responded to the survey.

For the eight short answer questions, the PCP's handwritten responses were first typed into excel. For the question 'What are the 4 most common medical conditions the patient visits you for?', responses were categorized by the first author as broad organ systems and reported based on the highest frequency of reason for visits to the PCP. The response to 'What 4 specialists are most commonly enlisted in this patient's care?' and 'What 4 outpatient clinics is this patient followed most often in?' could not be analyzed as most PCPs provided a physician name rather than a specialty or clinic. The responses to 'What 4 community supports are enlisted in this patient's care most often?' were diverse and could not be categorized. Qualitative responses to 'What interventions, if any, could prevent this patient's ED revisits and inpatient admissions?' and 'Is there anything else you would like to share?' were categorized under the headings 'PCP has suggestions' versus 'PCP has no suggestions for intervention'. PCP suggestions with similar themes were then compiled under broad categories (see Table 3). Qualitative responses to the question 'What patient factors, if any, predispose this patient to high-cost healthcare use?' were categorized as 'medical issues only' and 'additional contributing social factors. The 'Select-All-That-Apply' question 'Can you identify any 'Social Determinants of Health' that influence this patient's high-cost use? provided options; income and income distribution, education, unemployment, and job security, employment and working conditions, early childhood development, food insecurity, housing, social exclusion, social safety network, health services, aboriginal status, gender, race, disability, living situation, social supports and other. The number of selections for each factor were calculated and reported as a percentage of the total number of social factors selected.

\section{Results \\ High-User Demographics and Social Profile}

A total of 125 HUs were identified at UAH between Sep 1, 2015 and Sep 30, 2016. The total number of patients admitted to UAH during this study period was 23,643 . Thus, the $125 \mathrm{HUs}$ accounted for $0.5 \%$ of all patients admitted over that year. The 125 HUs (median 62 years old) had 688 admissions to UAH between Sep 2015-2016 accounting for 7716 acute hospital days. During the same time the UAH had a total of approximately 13,400 medical discharges and 11,800 surgical discharges. Thus, the HUs accounted for 688 of 25,200 (2.7\%) of all admissions at UAH that year. For the HUs, UAH hospitalizations were only the tip of the iceberg as they also had 1605 additional ED visits ( $41 \%$ at hospitals other than the UAH) and 181 admissions (21\% of their total) to other non-UAH hospitals elsewhere in the province. The HUs arrived by ambulance 662 times ( $41 \%$ of their UAH visits) with median 4 (IQR 2-7) ambulance arrivals in the year studied. Of these 125 HUs for 2015/16, 76 (61\%) had also been admitted at least once in Sep 2014/2015 and 58 (46\%) between Sep 2013/2014, as obtained from DIMR data. Table 1 summarizes the characteristics of these HUs. Almost half of HUs (46\%) were younger than 60 years and 70 (56\%) were receiving home care. 62 (50\%) were dependent for at least some ADLs as per documentation in patient charts, however, these were rarely broken down into specifics. Types of home supports included 19 HUs with personal care (15\% of HUs), 14 with medication assist (11\%), 14 with home care/support (11\%), 12 with wound care (10\%), 11 with bath assist (9\%) and 11 with respiratory services (9\%). Based solely on the last admission of the study period, the median number of discharge medications was 10 (IQR 7-14), median Charlson Comorbidity score was 2 (IQR 1-3), median LACE score was 14 (IQR 12-16), and median FAM-FACE-SG score (excluding financial components) was 32 (IQR 25-38) (Table 1). 
Table 1. Demographics and Social Characteristics of High-Users (HUs).

\begin{tabular}{|c|c|c|c|c|c|}
\hline High-user Variable & Total number & $\begin{array}{l}\text { Range } \\
(\min -\max )\end{array}$ & $\begin{array}{c}\text { Median } \\
\text { (Interquartile } \\
\text { Range } \\
25^{\text {th }}-75^{\text {th }} \text { ) }\end{array}$ & Subgroups & $\begin{array}{c}\text { Number of } \\
\text { HUs (\% of } \\
125 \text { HUs) }\end{array}$ \\
\hline $\begin{array}{l}\text { Total admissions and ED visits between Sep } \\
\text { 2015-16 }\end{array}$ & 2474 & $5-127$ & $14(10,22)$ & & \\
\hline Cumulative UAH LOS (days) & 7716 & $13-219$ & $49(35,73)$ & & \\
\hline UAH admissions & 688 & $3-11$ & $5(4,6)$ & & \\
\hline Non-UAH admissions & 181 & $0-13$ & $1(0,2)$ & & \\
\hline UAH ED visits & 941 & $1-41$ & $6(4,8)$ & & \\
\hline Non-UAH ED visits & 664 & $0-89$ & $1(0,3)$ & & \\
\hline Number of ambulance arrivals & 662 & $1-57$ & $4(2,7)$ & & \\
\hline Age (years) & & $22-95$ & $62(46,72)$ & & \\
\hline Number of discharge meds & & $0-30$ & $10(7,14)$ & & \\
\hline Charlson Comorbidity score $^{9}$ & & $0-15$ & $2(1,3)$ & & \\
\hline LACE Score ${ }^{5}$ (High risk $\geq 10$ ) & & $4-19$ & $14(12,16)$ & & \\
\hline $\begin{array}{l}\text { FAM-FACE-SG score }{ }^{8} \text { excluding Medifund \& } \\
\text { subsidized stay (High risk } \geq 14 \text { ) }\end{array}$ & & $10-50$ & $32(25,38)$ & & \\
\hline \multirow[t]{2}{*}{ Sex } & & & & Male & $66(53)$ \\
\hline & & & & Female & $59(47)$ \\
\hline \multirow{4}{*}{ Living facility at time of last admission } & & & & Home & $92(74)$ \\
\hline & & & & LTC & $12(10)$ \\
\hline & & & & Supportive Living & $11(9)$ \\
\hline & & & & No Fixed Address & $9(7)$ \\
\hline \multirow{3}{*}{ Prior or Current Home Care } & & & & $<6$ months & $25(20)$ \\
\hline & & & & $\geq 6$ months & $45(36)$ \\
\hline & & & & None & 55 (44) \\
\hline
\end{tabular}

ED = Emergency Department; LOS = length of stay; UAH = University of Alberta Hospital

\section{High-User Medical Profile}

Most (93\%) HUs (116) had at least one admission to a medical specialty and $51(41 \%)$ had at least one admission to a surgical specialty in the 13 months studied. Table S1 in the Appendix summarizes rates of admission and consultation amongst services. Of the HU hospitalizations, 28\% (185 admissions) were on GIM wards, 16\% (116) Pulmonary, 15\% (100) Hematology, and 15\% (98) Gastroenterology. The median number of services involved at the last admission (either as admitting or consulting service) was 2 (IQR 2,4) up to a maximum of 10 . The most consulted specialties were Surgical Specialties with 46 consults (16\% of all consults), GIM with 39 consults (13\%), Gastroenterology 34 (12\%),
Pulmonary 28 (9\%), Infectious Diseases 26 (9\%), Psychiatry 19 (6\%) and Hematology 18 (6\%) consults. About one third (34\%) of HUs (42) were admitted to critical care at some point over the study year at least once, with a total of 66 ICU admissions and 397 ICU days for these patients with a median of 2.6 days (IQR 0.8-11.1) per patient in the study year. Figure 1 displays the most commonly listed comorbidities under 'Past Medical History' during chart reviews. These listed comorbidities were categorized by grouping under predefined categories. Figure S1 in the Appendix displays the most common admitting diagnosis under ICD codes. As of the last admission, goals of care were documented under mandatory admission documentation as full 


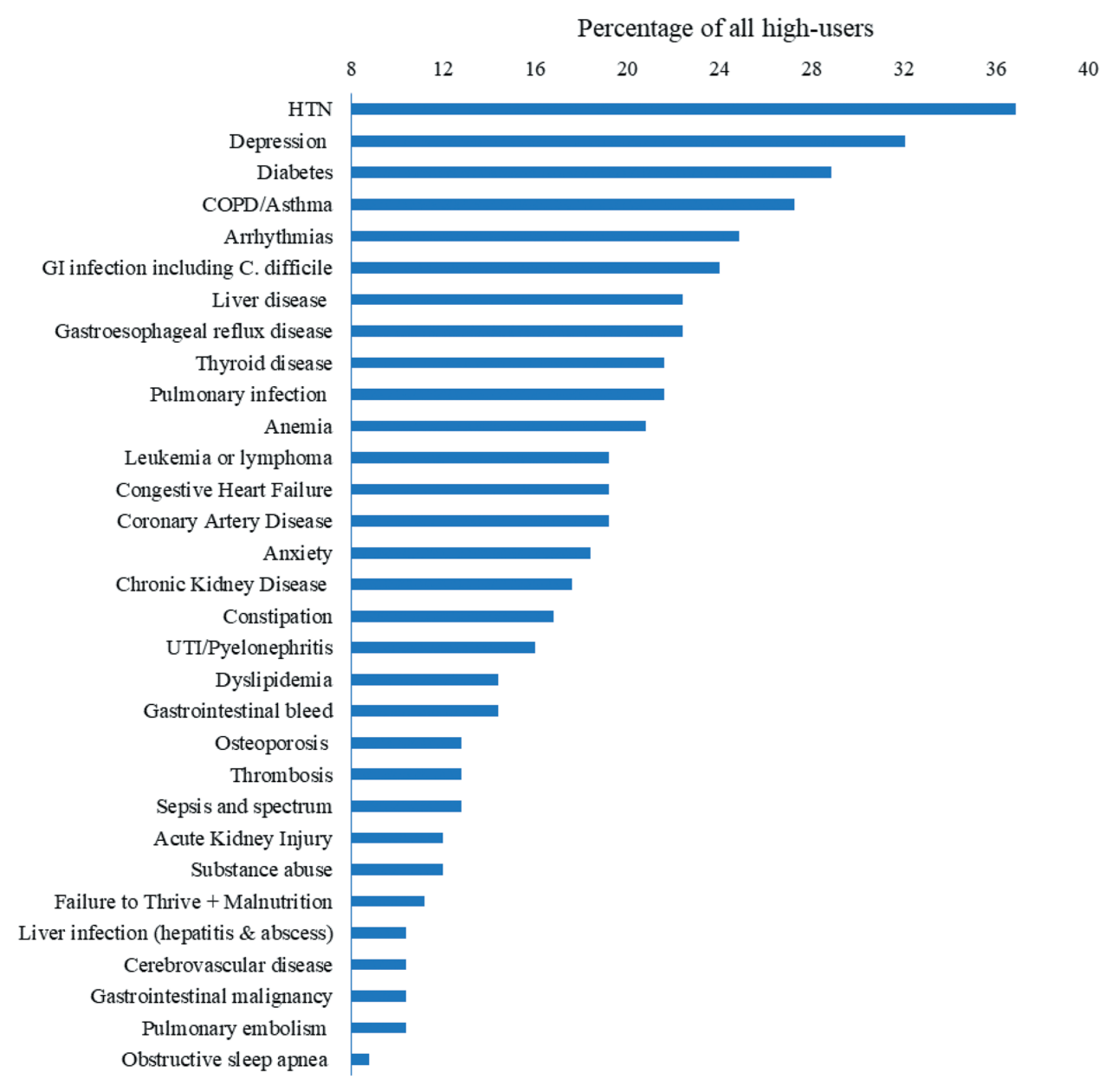

Figure 1. Most prevalent comorbidities amongst high-users (HUs).

resuscitation for $46 \%$ (58 HUs), resuscitation without CPR for $4 \%$ (5), ICU support without CPR and intubation for 7\% (9), medical management but no resuscitation or ICU support in $27 \%$ (34), comfort measures only in 11\% (14) and unknown/ presumed full resuscitation in $4 \%$ (5). At the time of analysis in February 2018, 54 (43\%) of the 125 HUs were deceased.

\section{Family Physician Affiliation and Survey Responses}

In our cohort, 96\% (120) of 125 HUs listed in their medical record that they had a PCP; 108 (86\%) were Family Physicians, 5 were General Internists, 3 were Cystic Fibrosis specialists, and 4 others listed a psychiatrist, medical oncologist, palliative care physician, and nurse practitioner. During surveys, 6 PCPs could not be contacted as their contacts were not available on the CPSA website or they were deceased. We received responses to 49 of the faxed 114 surveys ( $43 \%$ response rate); 4 declined participation and 9 responded stating that the patient is not affiliated with them or their clinic. Table 2 summarizes the PCP responses to the first 11 multiple-choice questions in the survey including duration of affiliation, frequency of visits, patient behaviors and attitudes, goals of care discussions, and discharge summaries. In cases where multiple options were selected, all options were included. Some PCPs did not respond to select questions. Question 12 (What is the patient's attitude to you?) is not reported in Table 2 as the PCP understanding of the question was variable and not accurately interpretable.

In the short answer section, when PCPs were asked about factors that predispose the patient to high use, prominent responses were limited resources and lack of social/home supports, low level of education/illiteracy, patient and family anxiety, personality traits and poor capacity. 16 PCPs responded that medical issues were the root of the problem while 24 PCPs believed that social factors additionally contributed, including lack of social supports which was suggested 15 times (17\% of 82 suggested social factors), disability in $11 \mathrm{HUs}$ (13\% of all social factors), living situation in $9(11 \%)$, and income and income distribution in 9 (10\%). Pulmonary and gastrointestinal conditions were the most common reasons for $\mathrm{HU}$ visits to the PCP office. Other general 
Table 2. Primary Care Physician (PCP) Responses to the First 11 MultipleChoice Questions on the Survey

\begin{tabular}{|c|c|}
\hline Multiple-Choice Questions & $\begin{array}{c}\text { \# of PCP } \\
\text { responses ( } \% \\
\text { responses out } \\
\text { of } 49 \text { ) }\end{array}$ \\
\hline $\begin{array}{l}\text { 1. Are you still the Primary Care Provider for this } \\
\text { patient? }\end{array}$ & $49(100)$ \\
\hline a. Yes & $28(57)$ \\
\hline $\begin{array}{l}\text { b. No, the patient transferred to another } \\
\text { provider }\end{array}$ & $3(6)$ \\
\hline c. No, the patient never followed up & $2(4)$ \\
\hline d. No, the patient is now deceased & $13(27)$ \\
\hline e. No, for other reasons & $3(6)$ \\
\hline $\begin{array}{l}\text { 2. If yes, for how long have you been this } \\
\text { patient's GP? }\end{array}$ & $44(90)$ \\
\hline a. $<1$ year & $5(10)$ \\
\hline b. $1-5$ years & $18(37)$ \\
\hline c. $6-10$ years & $8(16)$ \\
\hline d. $10-20$ years & $8(16)$ \\
\hline e. $>20$ years & $4(8)$ \\
\hline f. Not applicable & $1(2)$ \\
\hline No response provided & $5(10)$ \\
\hline $\begin{array}{l}\text { 3. How many times has the patient visited your } \\
\text { clinic in the last year? }\end{array}$ & $47(96)$ \\
\hline a. 0 & $16(33)$ \\
\hline b. $1-5$ & $14(29)$ \\
\hline c. $6-10$ & $5(10)$ \\
\hline d. $10-15$ & $4(8)$ \\
\hline e. $>15$ & $2(4)$ \\
\hline Note: Home visits/nursing home/LTC & $6(12)$ \\
\hline No response provided & $2(4)$ \\
\hline $\begin{array}{l}\text { 4. Does this patient visit you within } 2 \text { weeks of a } \\
\text { hospital visit? }\end{array}$ & $46(94)$ \\
\hline a. Always & $7(14)$ \\
\hline b. Mostly & $11(22)$ \\
\hline c. Occasionally & $12(24)$ \\
\hline d. Rarely & $6(12)$ \\
\hline e. Never & $7(14)$ \\
\hline No response provided & $3(6)$ \\
\hline
\end{tabular}

Table 2. Primary Care Physician (PCP) Responses to the First 11 MultipleChoice Questions on the Survey (continued)

\begin{tabular}{|c|c|}
\hline Multiple-Choice Questions & $\begin{array}{c}\text { \# of PCP } \\
\text { responses ( } \% \\
\text { responses out } \\
\text { of } 49 \text { ) }\end{array}$ \\
\hline $\begin{array}{l}\text { 5. Do you consistently receive discharge } \\
\text { summaries on the patient after hospital visits? }\end{array}$ & $46(94)$ \\
\hline a. Always & $18(37)$ \\
\hline b. Mostly & $16(33)$ \\
\hline c. Occasionally & $5(10)$ \\
\hline d. Rarely & $3(6)$ \\
\hline e. Never & $1(2)$ \\
\hline No response provided & $3(6)$ \\
\hline $\begin{array}{l}\text { 6. Does the patient miss appointments with } \\
\text { you? }\end{array}$ & $46(94)$ \\
\hline a. Never & $20(41)$ \\
\hline b. Rarely & $12(24)$ \\
\hline c. Occasionally & $5(10)$ \\
\hline d. Frequently & $5(10)$ \\
\hline e. Always & $1(2)$ \\
\hline No response provided & $3(6)$ \\
\hline $\begin{array}{l}\text { 7. Do you think this patient is managing chronic } \\
\text { diseases well? }\end{array}$ & $45(92)$ \\
\hline a. Yes & $20(41)$ \\
\hline b. Somewhat & $4(8)$ \\
\hline c. No & $8(16)$ \\
\hline d. Unsure & $7(14)$ \\
\hline No response provided & $4(8)$ \\
\hline $\begin{array}{l}\text { 8. Is the patient compliant with health } \\
\text { management recommendations? }\end{array}$ & $45(92)$ \\
\hline a. Yes & $31(63)$ \\
\hline b. Somewhat & $5(10)$ \\
\hline c. No & $5(10)$ \\
\hline d. Unsure & $3(6)$ \\
\hline No response provided & $4(8)$ \\
\hline
\end{tabular}

(continued) 
Table 2. Primary Care Physician (PCP) Responses to the First 11 MultipleChoice Questions on the Survey (continued)

\begin{tabular}{|c|c|}
\hline Multiple-Choice Questions & $\begin{array}{c}\text { \# of PCP } \\
\text { responses ( } \% \\
\text { responses out } \\
\text { of } 49 \text { ) }\end{array}$ \\
\hline $\begin{array}{l}\text { 9. Have you discussed Goals of Care with this } \\
\text { patient or family? }\end{array}$ & $44(90)$ \\
\hline a. Yes & $22(45)$ \\
\hline b. Partially & $2(4)$ \\
\hline c. No & $14(29)$ \\
\hline d. Cannot recall & $2(4)$ \\
\hline No response provided & $5(10)$ \\
\hline 10. Where does this patient live? & $43(88)$ \\
\hline a. Home alone & $8(16)$ \\
\hline b. Home with family/friends & $26(53)$ \\
\hline c. Assisted living facility & $3(6)$ \\
\hline d. Long-term care facility & $3(6)$ \\
\hline e. Homeless shelter & $0(0)$ \\
\hline f. Other & $3(6)$ \\
\hline No response provided & $6(12)$ \\
\hline $\begin{array}{l}\text { 11. What is the patient's attitude to his/her } \\
\text { medical condition? }\end{array}$ & $44(90)$ \\
\hline a. Aware and compliant & $31(63)$ \\
\hline b. Aware but non-compliant & $6(12)$ \\
\hline c. Unaware/indifferent & $1(2)$ \\
\hline d. Lacks capacity & $4(8)$ \\
\hline No response provided & $5(10)$ \\
\hline
\end{tabular}

*A total of 49 PCPs responded to surveys; some questions were skipped by some PCPs.

issues that were noted by their PCP but not picked up during chart reviews included insomnia, smoking cessation, pressure ulcers, fractures, fertility, prescription renewal, and poor mobility. When asked about recommendations for improvement, 14 PCPs provided one or more suggestions; these have been grouped into categories by the authors and presented in Table 3.

\section{Discussion}

There are 4 key findings in our work that deserve emphasis. First, amongst HUs, $41 \%$ of ED visits and $21 \%$ of readmissions were at other hospitals despite these patients having well-established links to staff at the main study hospital. Second, while it is not

Table 3. Compilation of Primary Care Physician (PCP) Recommendations for Improvement

\section{Targetable \\ Strategies \\ (Number of \\ PCPs who \\ made the \\ suggestion)}

\begin{tabular}{|c|c|}
\hline & Summary of PCP recommendations \\
\hline $\begin{array}{l}\text { Higher Level of } \\
\text { Care (5) }\end{array}$ & $\begin{array}{l}\text { - } \text { move to supportive living } \\
\text { - } \text { psychiatric-oriented facility } \\
\text { - direct readmission to hospice } \\
\text { - greater medical capacity at patient living } \\
\text { facilities }\end{array}$ \\
\hline $\begin{array}{l}\text { Better community } \\
\text { supports (7) }\end{array}$ & $\begin{array}{l}\text { - } \text { medication supports and better home care } \\
\text { - supports for individuals with cognitive issues } \\
\text { - early childhood development, aboriginal status } \\
\text { supports, family support, income support }\end{array}$ \\
\hline $\begin{array}{l}\text { Better access to } \\
\text { medical resources } \\
\text { (5) }\end{array}$ & $\begin{array}{l}\text { - home visits by RN/NPs, PCPs and/or specialists } \\
\text { - } 24 / 7 \text { access to PCPs } \\
\text { - } \text { quicker access to urgent surgeries } \\
\text { - } \text { patient's local pharmacy to stock infrequently } \\
\text { used meds }\end{array}$ \\
\hline $\begin{array}{l}\text { Targeting patient } \\
\text { behaviors (8) }\end{array}$ & $\begin{array}{l}\text { - health education to better understanding } \\
\text { primary condition } \\
\text { mental health resources for personality } \\
\text { disorders, anxiety, and opioid dependency } \\
\text { encourage patients towards proactive clinic } \\
\text { visits and better communication with their } \\
\text { physicians }\end{array}$ \\
\hline $\begin{array}{l}\text { Administrative } \\
\text { interventions (4) }\end{array}$ & $\begin{array}{l}\text { - detailed patient information sheets for clinic } \\
\text { visits and hospital discharges } \\
\text { - ensuring PCPs receive discharge summaries at } \\
\text { time of discharge } \\
\text { - efforts to improve and enhance communication } \\
\text { between specialists and primary care }\end{array}$ \\
\hline
\end{tabular}

surprising that HUs have multiple chronic conditions, high medication use, longitudinal patterns of high-use, and lower socioeconomic status, we were surprised that most of the highusers we identified had a regular PCP and lived at home. It is also noteworthy that PCP perspectives on HUs generally reveal positive health behaviors and attitudes, with $65 \%$ of responding PCPs stating the patient rarely or never missed appointments. $41 \%$ of PCPs believed the HU was managing his/her chronic diseases well, and only $10 \%$ thought the HUs were non-compliant with prescribed therapies (Table 2). Third, the greatest number of admissions of HUs were to GIM wards and GIM was also the most frequently consulted service when patients were admitted to 
a surgical or subspecialty service. Fourth, published readmission prediction scores have high predictive value in this cohort: at the time of their last admission in the study period, $88 \%$ of HUs had a high-risk LACE score $(\geq 10)$ whereas $99 \%$ had a high-risk FAM-FACE-SG score $\geq 14$.

The high rate of readmission and ED visits to the nonindex hospital is concerning a lack of continuity is associated with higher mortality in other studies. ${ }^{10,11}$ For example, Staples et al., 2014 found that $18 \%$ of patients who were re-admitted to an alternative hospital in their study had a $3 \%$ higher 30 -day mortality rate. ${ }^{10}$ While ambulance staff decide which hospital to take a patient to based on ED census numbers, consideration should be given to prioritize HUs so that they are preferentially taken to the hospital (and physicians, nurses, system) most familiar with them.

Our characterization of HUs is consistent with prior studies in that we found that hypertension, depression, diabetes, and obstructive lung disease were the most common comorbidities. ${ }^{12}$ We found that only $10 \%$ of our HUs lived in LTC, which is consistent with a report that $14 \%$ of HUs in another Canadian province (Ontario) lived in LTC. ${ }^{13}$ Moreover, our HUs tend to have a longitudinal pattern of increased use, consistent with an Ontario study that reported that $45 \%$ of adult HUs persisted as HUs in the subsequent year. ${ }^{3}$ Current and past healthcare utilization are strongly associated with HUs indicating a need for targeted interventions even for those patients with ongoing continuity of care. ${ }^{14}$

Although we identified HUs using a standard, CIHI-endorsed definition and were able to track all of their hospitalizations and ED visits anywhere in the province, there are some limitations to our study. For one, there are multiple other definitions of HUs in the literature based not on total LOS in one year, as used by the CIHI definition, but instead based on healthcare costs, ${ }^{3}$ population cost percentiles, ${ }^{15}$ number of readmissions regardless of $\operatorname{LOS}^{8}$ and use of other healthcare resources. We recognize that CIHI-defined HUs do not necessarily reflect those with the highest hospital costs. ${ }^{16} \mathrm{~A}$ second limitation is the possibility of response bias in our PCP surveys. PCPs had an overall favorable view of HUs. The $43 \%$ response rate may represent physicians who are more diligent and actively involved in patient care. Another limitation of our PCP surveys is that these were not done prospectively soon after a readmission occurred and therefore did not provide PCP feedback in real-time. The surveys did not ask PCPs to rate the 'preventability' of that readmission or identify factors/potential interventions that could have prevented that specific readmission. Instead, the survey only asked in a general sense about the factors contributing to high system use or potential interventions to reduce unnecessary use. There is also a selection bias in characterizing HUs as this study was conducted in a tertiary care teaching hospital and is not reflective of a community hospital. For example, the high readmission rates for hematology and gastroenterology were likely due to the high number of leukemia patients and the hepatology/liver transplant service at this centre. It is thus important to take the healthcare centre into account when generalizing admission patterns. There is also a survivor bias in characterizing HUs as they had to have at least three admissions and we did not include those who died during their first or second hospitalization within the study period. Additionally, while the CIHI definition includes all patient admissions in a year, we applied it only to a single hospital thereby missing out on hospitalizations at other centers and thus under-capturing $\mathrm{HU}$ patients.

In our surveys, only 14 (29\%) out of 49 PCPs provided suggestions for improvement. Our finding that most PCPs believed that $\mathrm{HU}$ readmissions were not preventable is consistent with prior studies in this area. For example, a systematic review of 34 studies found that the median proportion of readmissions deemed avoidable was $27 \%$, ranging from 5 to $79 \%$ between studies $^{5}$ and in another similar survey of PCPs of high user patients, $58 \%$ of PCPs believed that no interventions could prevent readmissions. ${ }^{17}$ Our study thus re-enforces the notion of 'unavoidability' of high user readmissions. On the other hand, a literature review suggested that 12 to $75 \%$ of readmissions might be preventable by patient education and pre- and postdischarge care ${ }^{18}$ and a Kaiser Permanente case series found that $47 \%$ of 30 -day readmissions might be preventable by targeting transition and follow-up care planning, medication management and advance care planning. ${ }^{19}$ Thus, the healthcare arena is gradually adopting a focus on transitions of care with a renewed emphasis on patient-centered care. Ultimately, even though HU readmissions are generally perceived as unavoidable, we must continue to identify modifiable system factors to intervene on.

In our surveys, a prominent recommendation by 5 PCPs was for higher levels of care and community supports including LTC, supportive living, psychiatric-oriented facilities, and hospice, as well as increased depth of medical care at these facilities. One PCP stated, "need more capacity to manage episodes in her facility as they will call the ambulance quite readily." There was also a suggestion for "efforts to improve and enhance communication between specialists and primary care" as only 34 (74\%) PCPs stated they mostly-always receive discharge summaries from hospital admissions before HU follow-up visits. PCPs also notably suggested increased mental health resources for patients with personality disorders, depression, anxiety, and opioid dependency; we found that depression and anxiety together accounted for 6.3\% (63) of all listed comorbidities (see Figure 1), psychiatry accounted for $6 \%$ of inpatient consults amongst HUs (Table S1) and 39\% (49) of HUs were on an antidepressant over the past year according 
to chart reviews. Thus, an important intervention would be to connect identified HUs with mental health resources and ensure they have appropriate community supports.

A popular recommendation by PCPs was for home visits whether by nurses, PCPs or even specialists; however, only 6 (13\%) of 46 PCPs stated that they do home/facility visits (ranging from weekly to 1-4 times per year) (see Table 2). In the US, there has been a push towards the multidisciplinary team-based PatientCentered Medical Home (PCMH) which provides a shift in focus from acute rescue to proactive maintenance of chronic diseases. ${ }^{20}$ The 'Virtual Ward' is another model which uses a predictive tool to identify HUs at risk of frequent readmissions and then provides intensive multidisciplinary ward-type care to these high user patients in a community setting. ${ }^{820-26} \mathrm{~A}$ Toronto-based trial by Dhalla et al. 2014 focused only on patients with a high LACE score and found no reduction in readmission rates with intensive post-discharge care transitions. ${ }^{27}$ However, another Community Virtual Ward model in Ireland designed to support older patients with complex social and health care needs found a reduction in ED presentations and unplanned hospital admissions using a proactive integrated multidisciplinary approach. ${ }^{24}$

Thus, future models should continue to incorporate a broader definition of HUs, as characterized in our study, and should focus on targeting social factors and preventative medicine in addition to care transitions. Predictive tools that use electronic medical records to extract information on patient characteristics are now being developed and would further improve readmission predictive analysis. ${ }^{28}$ Hospital physicians can also play a role by ensuring timely and effective communication with PCPs and connecting high user patients with adequate mental health resources and community supports. Potential next steps for hospital quality improvement projects is to use predictive models to firstly identify high-users and then engage identified HUs in systembased interventions to study their effectiveness in improving readmission outcomes. A future direction for our group is to develop a 'Virtual Hospital' for our HU patient population and investigate its effectiveness in reducing readmissions and $\mathrm{ED}$ visits.

\section{Conclusion}

In conclusion, our analysis of HUs identified characteristics that are consistent with prior studies and recognized pre-existing models. We found that most of the HUs we identified had a regular PCP and lived at home with home care and family supports. While HU patients were seen in all specialties, the greatest number were admitted to GIM wards and GIM was the most frequently consulted service when patients were admitted to a surgical or subspecialty service. While PCP suggestions do not necessarily correlate with specific HU characteristics, they do provide a wealth of frontline experience that we can build on to develop practical interventions. In keeping with prior literature, PCP perspectives in this study reinforce the notion that many high user readmissions are unavoidable and guide us to look away from individual patient characteristics and instead to look at system-based preventative and transitional care factors for targetable interventions. Future studies must focus on predicting HUs early on and studying the effect of suggested system-based interventions on preventing their readmissions.

\section{Funding/Support}

Alberta Health Services Quality Innovation Fund.

\section{Ethical Approval}

Research Ethics Board at the University of Alberta Hospital (Pro00073914).

\section{Other Disclosures and Disclaimers}

None.

\section{Previous Presentations}

None.

\section{Acknowledgements}

The authors wish to thank Alberta Health Services, Strategic Clinical Improvement Committee for their valuable assistance and access to resources. We thank the Data and Health Information Resources for compiling data on HUs. We thank Xing Sun for contacting the primary care physician offices. The authors thank the PCPs who responded to our surveys.

\section{References}

1. Guilcher SJT, Bronskill SE, Guan J, et al. Who are the high-users? A method for person-centred attribution of health care spending. PLoS ONE [Electronic Resource]. 2016;11(3).

2. Lown BA, McIntosh S, Gaines ME, et al. Integrating compassionate, collaborative care (the "triple C") into health professional education to advance the triple aim of health care. Acad Med 2016;91(3):310-16.

3. Wodchis WP, Austin PC, Henry DA. A 3-year study of high-users of health care. CMAJ 2016;188(3):182-88.

4. Canadian Foundation for Healthcare Improvement. [Internet]. Available at: https://www.cfhi-fcass.ca. Revised February 5, 2019. Accessed February 7, 2019.

5. Van Walraven C, Bennett C, Jennings A, et al. Proportion of hospital readmissions deemed avoidable: A systematic review. CMAJ 2011;183(7):402.

6. Bardsley M, Lewis G. Reflections from the NHS in England. Healthc Papers 2014;14(2):26-30.

7. Billings J, Dixon J, Mijanovich T, et al. Case finding for patients at risk of readmission to hospital: Development of algorithm to identify high risk patients. BMJ 2006;333(7563):327-30.

8. Low LL, Liu N, Lee KH, et al. FAM-FACE-SG: A score for risk stratification of frequent hospital admitters. BMC Med Inform Decis Mak 2017;17:35.

9. Charlson ME, Pompei P, Ales KL, et al. A new method of classifying prognostic comorbidity in longitudinal studies: Development and validation. J Chronic Dis 1987;40(5):373-83. 
10. Staples JA, Thiruchelvam D, Redelmeier DA. Site of hospital readmission and mortality: A population-based retrospective cohort study. CMAJ Open 2014;2(2):77.

11. McAlister FA, Youngson E, Kaul P. Patients with heart failure readmitted to the original hospital have better outcomes than those readmitted elsewhere. J Am Heart Assoc 2017;6(5).

12. Chechulin $Y$, Nazerian A, Rais S, et al. Predicting patients with high risk of becoming high-cost healthcare users in Ontario (Canada). Healthc Policy 2014;9(3):68-79.

13. Rosella LC, Fitzpatrick T, Wodchis WP, et al. High-cost health care users in Ontario, Canada: Demographics, socio-economic, and health status characteristics. BMC Health Serv Res 2014;14:532.

14. Condelius A, Hallberg IR, Jakobsson U. Hospital and outpatient clinic utilization among older people in the 3-5 years following the initiation of continuing care: A longitudinal cohort study. BMC Health Serv Res 2011;11:136.

15. Rais S, Nazerian A, Ardal S, et al. High-users of Ontario's healthcare services. Healthc Policy 2013;9(1):44-51.

16. Nguyen OK, Tang N, Hillman JM, et al. What's cost got to do with it? Association between hospital costs and frequency of admissions among "high-users" of hospital care. J Hosp Med (Online). 2013;8(12):665-71.

17. Gantayet A, Ang M, Cao X, et al. Persistent and non-persistent high-users of acute care resources: A deeper dive into the patient and system factors. Healthc Q 2017; 20(2):31-4.

18. Benbassat J, Taragin M. Hospital readmissions as a measure of quality of health care: Advantages and limitations. Arch Intern Med 2000;160(8):1074-81.

19. Feigenbaum P, Neuwirth E, Trowbridge L, et al. Factors contributing to allcause 30-day readmissions: A structured case series across 18 hospitals. Med Care 2012;50(7):599-605.

20. Ortiz G, Fromer L. Patient-centered medical home in chronic obstructive pulmonary disease. J Multidiscip Healthc 2011;4:357-65.

21. Lewis G, Vaithianathan R, Wright L, et al. Integrating care for high-risk patients in England using the virtual ward model: Lessons in the process of care integration from three case sites. Int J Integr Care 2013;13:e046.

22. Lewis G, Bardsley M, Vaithianathan $R$, et al. Do 'virtual wards' reduce rates of unplanned hospital admissions, and at what cost? A research protocol using propensity matched controls. Int J Care Pathw [Electronic Resource] 2011;11:e079.

23. Leung DYP, Lee DT, Lee IFK, et al. The effect of a virtual ward program on emergency services utilization and quality of life in frail elderly patients after discharge: A pilot study. Clin Interv Aging 2015;10:413-420.

24. Lewis C, Moore Z, Doyle F, et al. A community virtual ward model to support older persons with complex health care and social care needs. Clin Interv Aging 2017;12:985-993.

25. Jones J, Carroll A. Hospital admission avoidance through the introduction of a virtual ward. Br J Community Nurs 2014;19(7):330-334.

26. Pacho C, Domingo M, Nunez R, et al. Early postdischarge STOP-HF-clinic reduces 30-day readmissions in old and frail patients with heart failure. Rev Esp Cardiol 2017;70(8):631-38.

27. Dhalla IA, O'Brien T, Morra D, et al. Effect of a postdischarge virtual ward on readmission or death for high-risk patients: A randomized clinical trial. JAMA 2014;312(13):1305-12.

28. Zolbanin HM, Delen, D. Processing electronic medical records to improve predictive analytics outcomes for hospital readmissions. Decis Support Syst 2018;112:98-110.

\section{Appendix}

Supplementary Table S1. Rates of Admission and Consultation Amongst Medical Services

\begin{tabular}{|l|c|c|c|}
\hline \multicolumn{1}{|c|}{ Service } & $\begin{array}{c}\text { Ratio of \# } \\
\text { \% of HU } \\
\text { admissions } \\
\text { (\# of } \\
\text { admissions) } \\
\text { to \# HUs } \\
\text { accounting for } \\
\text { admissions } \\
\text { over the year }\end{array}$ & $\begin{array}{c}\text { \% of } \\
\text { specialties } \\
\text { consulted } \\
\text { on } \\
\text { inpatient } \\
\text { HUs (\# of } \\
\text { consults) }\end{array}$ \\
\hline $\begin{array}{l}\text { General } \\
\text { Internal } \\
\text { Medicine }\end{array}$ & $28(185)$ & $3.1(185 / 59)$ & $13(39)$ \\
\hline Surgery & $17(116)$ & $2.3(116 / 51)$ & $16(46)$ \\
\hline Pulmonary & $16(104)$ & $4.2(104 / 25)$ & $9(28)$ \\
\hline Hematology & $15(100)$ & $5.3(100 / 19)$ & $6(18)$ \\
\hline Gastroenterology & $15(98)$ & $3.3(98 / 30)$ & $12(34)$ \\
\hline Fam Med & $6(42)$ & $1.8(42 / 24)$ & $3(8)$ \\
\hline Nephrology & $3(17)$ & $3.4(17 / 5)$ & $2(7)$ \\
\hline Cardiology & $1(5)$ & $1.0(5 / 5)$ & $2(6)$ \\
\hline $\begin{array}{l}\text { Direct } \\
\text { admission to } \\
\text { ICU/CCU }\end{array}$ & $0(3)$ & $1.5(2 / 3)$ & Not available \\
\hline Geriatrics & $0(2)$ & $1.0(2 / 2)$ & $0(1)$ \\
\hline Psychiatry & $0(1)$ & $1.0(1 / 1)$ & $6(19)$ \\
\hline Neurology & $0(0)$ & N/A & $2(5)$ \\
\hline Infectious & N/A & N/A & $9(26)$ \\
\hline Diseases & N/A & N/A & $5(14)$ \\
\hline Palliative care & N/A & N/A & $4(12)$ \\
\hline Transplant & N/A & N/A & $2(5)$ \\
\hline Pain service & N/A & N/A & $1(2)$ \\
\hline Endocrinology & N/A & $0(1)$ \\
\hline Rheumatology & & & \\
\hline
\end{tabular}


Supplementary Table S2. Survey Faxed to the Primary Care Physicians (PCPs) of High-Users (HUs)

Dear Dr. ---------,

Mr/Ms. -------- is a high-cost user of the University of Alberta Hospital acute care services and has documented you as his/her family physician.

Can you confirm that $\mathbf{M r} / \mathbf{M s}$. ---------- has ever been your patient?

$\underline{\text { NO}}$, I have never seen this patient.

Thank you. You have completed this survey.

Please fax the questionnaire back to us at

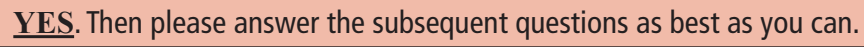

1. Are you still the primary care provider for this patient?
a. Yes
b. No, the patient transferred to another provider
c. No, the patient never followed up
d. No, the patient is now deceased
e. No, for other reasons

2. If yes, for how long have you been this patient's GP?
a. $<1$ year
b. $1-5$ years
c. $6-10$ years
d. $10-20$ years
e. $>20$ years
f. Not applicable

3. How many times has the patient visited your clinic in the last year?
a. 0
b. $1-5$
c. $6-10$
d. $10-15$
e. $>15$ 
4. Does this patient visit you within 2 weeks of a hospital visit?

a. Always
b. Mostly
c. Occasionally
d. Rarely
e. Never

5. Do you consistently receive discharge summaries on the patient after hospital visits?

\begin{tabular}{|l}
\hline a. Always \\
\hline b. Mostly \\
\hline c. Occasionally \\
\hline d. Rarely \\
\hline e. Never
\end{tabular}

6. Does the patient miss appointments with you?

\begin{tabular}{|l}
\hline a. Never \\
\hline b. Rarely \\
\hline c. Occasionally \\
\hline d. Frequently \\
\hline e. Always
\end{tabular}

7. Do you think this patient is managing his/her chronic diseases well?
a. Yes
b. Somewhat
c. No
d. Unsure
e. Not applicable

8. Is the patient compliant with health management recommendations?
a. Yes
b. Somewhat
c. No
d. Unsure
e. Not applicable 


\section{Have you discussed Goals of Care with this patient or his/her family?}
a. Yes
b. Partially
c. No
d. Cannot recall
e. Not applicable

\section{Where does this patient live?}

\section{a. Home alone}

b. Home with family/friends

c. Assisted living facility

d. Long-term care facility

e. Homeless shelter

f. Other

\section{What is the patient's attitude to his/her medical condition?}
a. Aware and compliant
b. Aware but non-compliant
c. Unaware/indifferent
d. Lacks capacity
e. Other

12. What is the patient's attitude to you?
a. Very good
b. Good
c. Neutral
d. Poor
e. Very poor

13. What top 4 medical conditions does the patient visit you for?

14. What top 4 specialists are enlisted in this patient's care?

15. What top 4 outpatient clinics is this patient followed in?

16. What top 4 community supports are enlisted in this patient's care?

17. What interventions, if any, could prevent this patient's Emergency Department revisits and inpatient readmissions?

18. What patient factors, if any, predispose this patient to high-cost healthcare use? 


\section{Can you identify any 'Social Determinants of Health' that influence this patient's high-cost use? Select all that apply.}

- Income and Income Distribution

\section{- Education}

- Unemployment and Job Security

- Employment and Working Conditions

- Early Childhood Development

- Food Insecurity

- Housing

- Social Exclusion

- Social Safety Network

- Health Services

- Aboriginal Status

- Gender

- Race

- Disability

- Living situation

- Social supports

- Other:

20. Is there anything else you would like to share?

Admitting Diagnosis per International Classification of Diseases (ICD) Codes

Diseases of the respiratory system

Diseases of the digestive system

Injury, poisoning and certain other consequences

Diseases of the blood and blood-forming organs

Diseases of the circulatory system

Neoplasms

Endocrine, nutritional and metabolic diseases

Symptoms, signs and abnormal labs

Factors influencing health status and contact

Diseases of the genitourinary system

Certain infectious and parasitic diseases

Diseases of the skin and subcutaneous tissues

Mental and behavioural disorders

Diseases of the musculoskeletal system and connective tissues

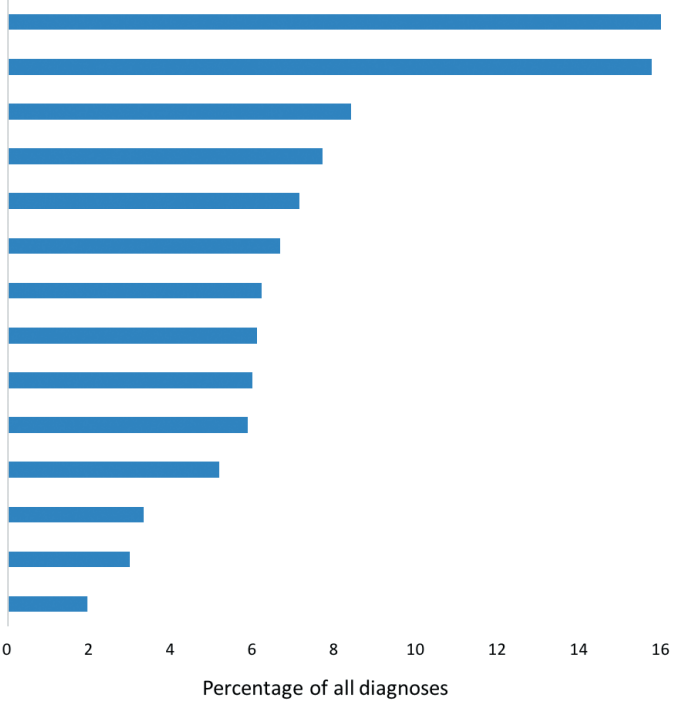

Figure S1. Admitting diagnosis based on International Statistical Classification of Disease (ICD) codes as a percentage of all diagnoses. 